\title{
OS REFLEXOS DA OPERAÇÃO MÃOS LIMPAS E DO CASO TORTORA NA COLABORAÇÃO PREMIADA BRASILEIRA
}

\author{
THE REFLECTIONS OF THE CLEAN \\ HANDS OPERATION AND THE TORTORA \\ CASE IN THE BRAZILIAN AWARD- \\ WINNING COLLABORATION
}

\author{
Maria Victória Jaeger Gubert ${ }^{1}$
}

Resumo: $\mathrm{O}$ que se pretende com o presente artigo é a análise dos ordenamentos jurídicos brasileiro e italiano, os quais, embora geograficamente distantes, são muito semelhantes entre si, em especial duas das maiores operações contra a corrupção já desenvolvidas no mundo: a Operação Mãos Limpas, ocorrida na Itália nos anos 90 , e a presente Operação Lava Jato no Brasil. Uma breve análise do que ocorreu no país europeu se faz de extrema importância para tentar prever o caminho pelo qual o Brasil está trilhando, buscando impedir que os mesmos erros se repitam. Por fim, examinar como se desenvolveu o Caso Tortora, em que delações falsas e um precário conjunto probatório foram usados para condenar um homem inocente como mafioso, também se mostra de essencial importância, a fim de demonstrar a realidade obscura da colaboração premiada, realidade esta que ninguém parece querer admitir que existe.

Palavras-chave: Colaboração premiada. Operação Mãos Limpas. Operação Lava Jato. Caso Tortora. Corrupção.

Abstract: The purpose of this article is to analyze the Brazilian and the Italian legal systems, which, although geographically distant, are very similar to each other, especially two of the largest anti-corruption operations ever developed in the world: the Operation Clean Hands, which occurred in Italy in the 1990s, and the current Operation Car Wash in Brazil. A brief analysis of what happened in the European country is extremely important in trying to predict the path Brazil is taking, seeking to prevent the same mistakes from repeating themselves. Finally,

1 Bacharela em Direito pela Universidade Federal de Santa Catarina (UFSC). Pósgraduanda em Direito Público pela Escola Superior da Magistratura do Estado de Santa Catarina (Esmesc) e exerce a função de residente judicial. E-mail: mariavictoriajg@ gmail.com. 
examining how the Tortora Case has been developed, in which false allegations and a precarious set of evidence were used to convict an innocent man as a mobster, is also of vital importance in order to demonstrate the obscure reality of the award-winning collabo- ration, a reality that nobody seems to want to admit that exists.

Keywords: Award-winning Collaboration. Operation Clean Hands. Operation Car Wash. Tortora Case. Corruption.

\section{INTRODUÇÃO}

No cenário em que o Brasil se encontra, principalmente em meio a esta crise político-econômica e, até mesmo, jurídica, é muito importante tentar prever o que o futuro nos reserva a fim de prevenir possíveis erros. Para isso, aquele bom e velho entendimento de que é necessário observar o passado para que se possa entender o futuro se faz tão presente.

O Brasil é um país que, desde sempre, buscou muita inspiração no exterior. O Direito brasileiro, em específico, tem suas raízes fora das fronteiras do país, sendo Estados Unidos, Alemanha e Itália apenas alguns exemplos de ordenamentos jurídicos usados como base para a formação da legislação brasileira.

$\mathrm{O}$ instituto da delação premiada não foge à regra. $\mathrm{O}$ modelo em vigor no Brasil passou por diversas modificações no decorrer do tempo, desde seu surgimento nas Ordenações Filipinas até a versão atual prevista pela Lei n. 12.850/2013, que regula o tratamento jurídico das organizações criminosas no país.

Observar os rumos da colaboração premiada no Brasil, mas, principalmente, o modo como ela vem sendo aplicada na prática na Operação Lava Jato é essencial para entender qual o futuro da delação no Brasil. Todavia, tal discussão não pode destoar do estudo de um dos ordenamentos jurídicos no qual o Brasil busca tanta inspiração: o italiano. Com efeito, mais importante do que um exame das leis desse país europeu é a análise de como essas foram e são aplicadas na prática. 
Com isso, o presente ensaio foi dividido em três tópicos. O primeiro dedica-se à breve apresentação de como foi desenvolvida a Operação Mãos Limpas nos anos 90 na Itália, bem como seus resultados.

Já a segunda parte do artigo é destinada à análise da atual Operação Lava Jato no Brasil, podendo-se destacar diversos pontos comuns com a ação italiana, muito embora sejam separadas por mais de duas décadas e tenham se desenvolvido em países de continentes diferentes.

Por fim, no terceiro tópico, narrar-se-á o famoso Caso Tortora, ocorrido na Itália entre 1983 e 1987, buscando apontar as falhas existentes em um instituto tão importante para o direito processual penal contemporâneo como a colaboração premiada, sem, porém, desmerecê-lo. Com isso, será possível observar os erros cometidos em um país no qual o Brasil tanto inspira seu Direito e, a partir deles, motivar o debate sobre o melhor modo da aplicação prática da colaboração premiada na realidade brasileira.

Para tanto, empregar-se-á ao ensaio o método de abordagem indutivo, recorrendo-se à técnica de documentação indireta, com pesquisa bibliográfica e documental, promovendo um estudo comparativo entre os ordenamentos jurídicos brasileiro e italiano, principalmente sua aplicação prática na luta contra a corrupção em ambos os países.

\section{OPERAZIONE MANI PULITE: A MAIOR LUTA CONTRA A CORRUPÇÃO NA ITÁLIA}

Em 1992, iniciou, em Milão, aquela que viria a ser a maior operação contra a corrupção já desenvolvida na Itália, a chamada Mani Pulite. Em seu início, não se esperava que uma ação envolvendo um caso, aparentemente, isolado de pagamento de propinas envolvendo a entidade filantrópica Pio Alberto Tri- 
vulzio fosse o ponto de partida para a descoberta de uma rede de corrupção impregnada na cidade de Milão, que passou a ser conhecida como "Tangentopoli" ou "Cidade da Propina", bem como no restante do país.

Naquele ano, a polícia milanesa e o Procurador da República Antonio Di Pietro foram informados pelo empresário Luca Magni da recorrente prática de atos ímprobos pelo Presidente do Pio Alberto Trivulzio, Mario Chiesa, o qual, à época, também era membro do Partido Socialista Italiano, um dos partidos políticos mais envolvidos nos escândalos que viriam a surgir. Segundo Magni, Chiesa havia exigido $10 \%$ do valor do contrato de 140 milhões de liras em troca da vitória de sua empresa de limpeza Ilpi (Impresa Lombarda Pulizie Industriale) em processo licitatório envolvendo a entidade filantrópica (BIONDANI, 2017).

Preso pela prática de concussão ao ser flagrado recebendo metade da quantia acordada, Mario Chiesa foi o primeiro a colaborar com a justiça, fazendo surgir cada vez mais nomes de envolvidos em esquemas de corrupção, em um "effetto-domino che fa crollare il sistema" (BIONDANI, 2017), ou, em tradução literal, em um "efeito dominó que faz ruir o sistema". Com o pontapé inicial de Chiesa, muitos outros políticos e empresários vieram à tona delatar, em uma tentativa de amenizar as consequências de seus atos, prestes a serem revelados ao público.

Com a onda de colaborações, mais casos de corrupção foram sendo descobertos pelas autoridades italianas, chegando à empresa petrolífera estatal Enimont, considerada a "madre di tutte le tangenti", ou, em tradução literal, a "mãe de todos os subornos". (SANTE, 2015).

Formada pelas empresas pública ENI (Ente Nazionale Idrocarburi) e privada Montedison, subsidiária do grupo Ferruzi, Enimont teve suas operações paralisadas após Raul Gardini, 
líder do grupo Ferruzi, tentar se tornar acionista majoritário da empresa, buscando "[...] o controle total do setor químico italiano, apoderando-se de uma posição de destaque entre os concorrentes internacionais (ao menos entre os 10 primeiros grupos químicos mundiais)" (SANTE, 2015, tradução nossa)².

Essa tentativa de tomar o controle da Enimont por parte de Gardini gerou uma situação de crise na empresa, cujas relações com outras empresas foram estremecidas, sendo, então, Sergio Cusani nomeado interventor no caso.

Enimont passou a ser alvo da ação quando Cusani, a mando do grupo Ferruzi, em razão da crise que se instaurava com a paralisação das atividades da petrolífera, começou a vender parte de suas ações ao Estado italiano em contratos superfaturados para possibilitar o repasse de propinas a políticos como Bettino Craxi, ex-primeiro ministro italiano, líder do Partido Socialista Italiano (PSI) e um dos principais alvos da Mãos Limpas.

O sucesso do avanço da Operação Mãos Limpas foi dado, principalmente, à reação do povo. Por diversas vezes tentaram conter a Mani Pulite, mas a população estava atenta ao caso graças à mídia e impedia a sua paralisação. A título exemplificativo, no ano seguinte à deflagração da ação, o Parlamento italiano negou autorização para que Bettino Craxi fosse processado criminalmente, alegando a sua imunidade parlamentar. Todavia, o veto parlamentar não passou em branco. Ciente da situação, no dia seguinte uma multidão de pessoas esperou Craxi em frente ao hotel onde o político estava hospedado e, enquanto o político saía do local, atirava moedas em sua direção, simbolizando o uso de dinheiro público de forma indevida (MORO, 2004).

A Operação Mani Pulite veio a ter fim dois anos depois de seu início, em 1994. Durante esse período, diversos polí-

2 “[...] il controllo totale del settore chimico italiano, arrogandosi una posizione di rilievo anche fra le concorrenti internazionali (almeno fra i primi 10 gruppi chimici mondiali)". 
ticos foram investigados e processados e, como resultado, os partidos mais importantes no cenário político italiano após a Segunda Guerra Mundial e também os mais envolvidos nos escândalos, o Partido Socialista Italiano e a Democracia Cristã, foram praticamente extintos com a grande rejeição do povo nas urnas nas eleições daquele mesmo ano, recebendo, respectivamente, apenas 2,2\% e 11,1\% dos votos (MORO, 2004).

Por tal razão, é que é dito que

O escândalo, conhecido como Tangentopoli (Cidade da Propina), causou um terremoto de forças sem precedentes. Foi tão poderoso e - em certo grau - tão inesperado que as fundações do estabelecimento político da Itália foram (praticamente) reduzidas a escombros, tendo de ser reconstruído a partir do zero. (NAVARRIA, 2016, tradução nossa). ${ }^{3}$

No entanto, embora a Operação tenha sido bem executa$\mathrm{da}$, trazendo à tona um grande problema que impregnava a política italiana, os resultados obtidos não foram exatamente os esperados. Não obstante muitos políticos tenham sido investigados e processados, poucos foram efetivamente punidos, principalmente em razão da prescrição, a ser tratada mais adiante, e da criação de leis descriminalizantes após o término da ação. A impunidade foi, portanto, um fator predominante no cenário pós-Mãos Limpas.

Ao final dos processos da Operação Mãos Limpas, descontadas as prescrições e as consequências das leis de descriminalização, o resultado foi de $5 \%$ de absolvição no mérito. Isso poderia ter inibido novas práticas, mas o saldo positivo das decisões de mérito foi praticamente neutralizado pelas inúmeras leis salva-corruptos que o Parlamento italiano editou. O recado maior que se passou aos políticos foi de que é possível continuar na trilha da corrupção e desvio de verbas, pois sempre há um compadrio para salvar boa parte

3 "The scandal, known as Tangentopoli (Bribesville), caused an earthquake of unprecedented force. It was so powerful and - to a certain degree - so unexpected that the foundations of Italy's political establishment were (mostly) reduced to rubble, having to be rebuilt from scratch". 
dos envolvidos. (CHEMIM, 2017, p. 227).

Além disso, a operação parece não ter surtido o efeito esperado na mentalidade da população, tão enfurecida no decorrer das investigações e dos processos. $\mathrm{Na}$ oportunidade de reverter o cenário político e de eleger novos indivíduos em busca de efetivas mudanças, o povo preferiu esquecer o caos pelo qual a política italiana recém passara e elegeu $17 \%$ de um total de $36 \%$ dos políticos investigados pela Mãos Limpas que concorreram novamente às eleições (CHEMIM, 2017, p. 19).

O cenário final da Operazione Mani Pulite foi, portanto, frustrante para todos, autoridades e população. O sentimento de esperança que tomara conta do povo no início e no decorrer das investigações e dos processos, na crença de uma verdadeira limpeza no governo e no sonho de um país livre de corrupção foram tão logo substituídos pela decepção por conta do insucesso dos resultados obtidos.

\section{A OPERAÇÃO LAVA JATO E AS SEMELHANÇAS ENTRE BRASIL E ITÁLIA}

O que ocorreu no Brasil foi bem parecido com o que se desenvolveu na Itália nos anos 90. A Lava Jato, antes mesmo de sequer ser considerada uma operação e de receber esse nome, teve seu início em março do ano de 2014 em Curitiba, Paraná. Tudo começou perante a Justiça Federal do Estado, com a investigação da prática de atos ilícitos por uma rede de quatro doleiros: Nelma Kodama, Raul Srour, Alberto Youssef e Carlos Habib Chater.

Poucos dias depois, veio à tona um caso, a princípio, isolado de suspeita de lavagem de dinheiro envolvendo um veículo Land Rover doado ao ex-diretor de Abastecimento da Petrobras, Paulo Roberto Costa, por meio do doleiro Alberto Youssef.

Paulo Roberto da Costa foi preso e, no decorrer das investigações, foi revelado um extenso esquema de corrupção envol- 
vendo partidos políticos e grandes empresas como a Petrobras e a Odebrecht. O modus operandi era sempre o mesmo: o superfaturamento de contratos públicos para mascarar as propinas.

A Operação Lava Jato ainda não teve seu fim e vem tomando proporções cada vez maiores, desvendando uma grande rede de corrupção até então oculta aos olhos das autoridades. No Estado do Paraná, por exemplo, até setembro de 2018, a operação buscava o ressarcimento de cerca de 38,1 bilhões de reais aos cofres públicos, dinheiro que havia sido desviado em esquemas de corrupção. Para exemplificar a amplitude da operação, basta observar a quantidade de indivíduos já condenados em primeiro grau no referido Estado, que totalizam 211, somando todas as penas 2.013 anos, 8 meses e 20 dias (BRASIL, 2018a).

Os grandes números se repetem em outras jurisdições. No Estado do Rio de Janeiro, por exemplo, até a data de 14 de março de 2018, já haviam sido ressarcidos 452,2 milhões de reais ao erário em multas compensatórias decorrentes de acordos de colaboração. As condenações no Estado, por sua vez, contabilizam 523 anos e 8 meses de reclusão (BRASIL, 2018b).

Foi a Operação Lava Jato a primeira grande ação a colocar em prática a recém instaurada Lei n. 12.850/2013, que dispõe sobre o tratamento dado às organizações criminosas, definindo também, de forma inédita no ordenamento jurídico brasileiro, o procedimento da colaboração premiada, estabelecendo seus limites e benefícios.

O primeiro delator da Operação Lava Jato a vir à tona usufruir de seus benefícios foi Paulo Roberto Costa, que, em 27 de agosto de 2014, formalizou acordo de colaboração com a justiça junto do Ministério Público Federal. Investigado na Lava Jato pela prática de crimes de peculato, corrupção e lavagem de dinheiro oriundo de crimes contra a Administração Pública, bem como de participação em organização crimino- 
sa, Paulo Roberto Costa teria usado da sua posição enquanto diretor da Petrobras para cometer fraudes em contratações e desviar verbas, somando dezenas de milhões de reais de prejuízo aos cofres públicos do país.

Em troca das informações prestadas, o colaborador recebeu diversos benefícios processuais como a possibilidade do cumprimento da prisão cautelar e das demais penas criminais na forma de prisão domiciliar, prevista na cláusula quinta, inciso I, alínea "a", do acordo homologado pelo Ministro Teori Zawascki (BRASIL, 2014).

A partir das suas declarações, assim como aconteceu na Itália durante a Operação Mãos Limpas, uma corrida contra o tempo começou entre os envolvidos nos esquemas que começavam a ser descobertos pelas autoridades. O quesito "novidade" das informações trazidas pelos delatores é muito importante para que seja avaliado pelo órgão acusatório ou pela autoridade policial qual o benefício equivalente como contraprestação.

Em delitos como os investigados pela Lava Jato, a obscuridade é característica predominante, sendo praticamente impossível para as autoridades tomarem conhecimento da prática dos mesmos pelas organizações criminosas para que possam agir de maneira a desestruturá-las. É por isso que

[...] a colaboração de um investigado funciona como um guia, um catalisador, que otimiza o emprego de recursos públicos, direcionando-os para diligências investigatórias com maior perspectiva de sucesso. É como se o investigador caminhasse dentro de um labirinto e a cada passo deparasse com muitos caminhos possíveis. A colaboração é uma oportunidade para que o investigador espie por cima do labirinto e descubra quais são os melhores caminhos, isto é, aqueles com maior probabilidade de sucesso na angariação de provas. (DALLAGNOL, 2015a).

No entanto, essa corrida contra o tempo entre os delatores não é o único ponto em comum entre as duas operações. Embo- 
ra Mani Pulite tenha sido desenvolvida em um país europeu há mais de duas décadas, seus ensinamentos vem sendo empregados na Lava Jato como forma de aprimorar a operação brasileira.

[...] não há como não notar as incríveis semelhanças entre Brasil e Itália quando se trata de política, futebol, paixão popular, preconceitos regionais (entre o Norte e o Sul no caso da Itália ou entre o Sul e o Nordeste no caso do Brasil), afrouxamento ético, corrupção institucionalizada, descuido no trato privado da coisa pública e também da legislação penal e processual penal benevolente com a criminalidade do colarinho-branco. (CHEMIM, 2017, p. 08).

Dentre os vários pontos semelhantes entre as duas operações, pode-se destacar, em primeiro lugar, a cultura dos países. Tanto na Itália quanto no Brasil, é muito conhecida a vontade de tirar vantagem de tudo a todo custo. No Brasil, a prática até recebeu o nome de "jeitinho brasileiro", mas também na Itália é exercida.

Por isso, o comportamento dos políticos brasileiros e italianos acaba sendo semelhante. Uma vez apontados como partícipes ou autores de crimes contra o erário, os políticos de ambos os países, em geral, não procuram deixar seus cargos enquanto as investigações ou o processo se desenvolvem, pelo contrário: buscam permanecer o maior tempo possível na função para poder usufruir das proteções que a mesma lhes confere, como imunidades e foro privilegiado. No Brasil e na Itália, a mentalidade dos políticos é a de que a renúncia ao cargo caracteriza uma confissão de culpa, não sendo, portanto, uma opção viável, mas o último recurso (CHEMIM, 2017, p. 08).

É em razão disso que se criou um forte sentimento de desconfiança da população desses países para com o governo a partir do momento que as Operações Mãos Limas e Lava Jato começaram. Como visto, na Itália, o Partido Socialista Italiano e a Democracia Cristã foram extintos após os escândalos, desprezo que já se pode observar em relação ao Partido dos Trabalhadores no Brasil. 
Se não bastasse, em ambos os países, há aquilo que Rodrigo Chemim (2017, p. 17) chama de "naturalização da corrupção sistêmica", ou seja, a grande parte da população encara com normalidade a existência corrupção na política, como se fosse algo natural e inerente a ela. Por isso, os investigados e os acusados pela prática de crimes contra a Administração Pública não só confessam a ciência da corrupção na política, como justificam suas ações afirmando que a realidade do país é esta e que não foi o sujeito ou seu partido político que a criaram.

A naturalidade é tanta que a propina já não mais é uma contraprestação de algo específico, mas apenas uma mera formalidade para que os interessados em lucrar às custas da Administração Pública mantenham um bom relacionamento para com as autoridades do governo. Excelente exemplo é o chamado "Setor de Operações Estruturadas" da empreiteira Odebrecht, departamento especializado em cuidados de propinas e operações ilegais.

Além disso, existe a figura que a criminologia entitula de "seletividade do direito penal", segundo a qual

[...] o poder punitivo do Estado funciona bem contra pessoas que, em decorrência de seu meio, grau de instrução e condições de vida, são mais vulneráveis, ao passo que pessoas de classes econômica e politicamente mais fortes, mesmo que pratiquem crimes, não são selecionadas na mesma medida. Estas, portanto, não costumam receber punições pelos seus atos e não se sentem ameaçadas pela norma penal. (CHEMIM, 2017, p. 32).

Há todo um preconceito enraizado na cultura de ambos os países, preconceito que ultrapassa a mera leitura fria da letra da lei, dizendo respeito a questões de raça, cor, religião e condição financeira do réu, condições que deturpam a interpretação da norma a depender do caso apresentado.

A questão do preconceito é muito clara e basta observar o perfil dos presos no Brasil para entender sobre o que se trata 
essa insegurança. Até o ano de 2015, no Estado do Paraná, em um universo de 30 mil presos, apenas 53 lá estavam a cumprir pena pela prática de corrupção, porém nenhum deles se adequava ao "perfil do corrupto que desvia milhões" (DALLAGNOL, 2015b), em que pese seja de conhecimento público como a política brasileira é impregnada de crimes de tal natureza.

Os encarcerados em razão da prática de tais delitos são, em regra, aqueles indivíduos que, ao serem flagrados embriagados na condução de veículo automotor, tentam subornar o policial a fim de evitar multas e prisão. É muito difícil encontrar um político e um grande empresário presos pelo desvio de dinheiro público.

[...] o processo penal virou "grande negócio" para rico, porque sem pudores, brada-se que "delação não é para pobre”. Claro, pobre é chicote e Súmula 231 do STJ, ou seja, a pena não pode baixar do mínimo pela confissão, mas pode ser reduzida/extinta pela delação (ROSA, 2016, p. 295).

Faz-se necessário, portanto, unificar a lente dos juristas, para que todos passem a, de fato, interpretar a lei do mesmo modo em todos os casos, sob pena de continuar perpetuando esse sentimento de insegurança jurídica em nosso sistema.

No entanto, o ponto mais gritante na comparação entre os dois ordenamentos jurídicos e as duas operações anticorrupção é a impunidade, a qual é resultado direto da tolerância das legislações italiana e brasileira. No Brasil, por exemplo, o Título XI do Código Penal que dispõe sobre os crimes contra a Administração Pública, a penalidade máxima lá encontrada é de 12 anos, o que acarreta em um prazo prescricional de 16 anos, segundo o art. 109 do respectivo diploma legal.

Ocorre que, na prática, réus que respondem por tais delitos, usualmente, são primários e inexistem circunstâncias capazes de majorar a pena no decorrer da dosimetria, sendo comuns condenações que não passem de 2 anos de reclusão.

E mais: 
Uma pena inferior a 4 anos, quando não é cumprida em regime aberto, em casa e sem fiscalização (na falta de casa de albergado), é substituída por penas restritivas de direitos - ou seja, prestação de serviços à comunidade e doação de cestas básicas. Para piorar o cenário, decretos de indulto natalino determinam a extinção dessas penas após apenas um quarto delas terem sido cumpridas, ainda que penas alternativas não gerem superlotação carcerária, a qual o indulto, em tese, buscaria remediar. (DALLAGNOL, 2015b).

Deve-se considerar, ainda, a incidência da chamada prescrição retroativa, prevista no parágrafo $1^{\circ}$ do art. 110 do Código Penal.

Segundo Cezar Roberto Bitencourt,

A prescrição retroativa leva em consideração a pena aplicada, in concreto, na sentença condenatória, contrariamente à prescrição in abstrato, que tem como referência o máximo de pena cominada ao delito. A prescrição retroativa (igualmente à intercorrente), como subespécie da prescrição da pretensão punitiva, constitui exceção à contagem dos prazos do art. 109. (2015, p. 411).

Logo, se ao indivíduo é cominada uma pena de 2 anos ao final do cálculo dosimétrico, seu prazo prescricional equivalente é de 4 anos, conforme o já mencionado art. 109 do Código Penal. Sendo a realidade dos crimes praticados por organizações criminosas revestida de obscuridade, é provável que a prática do delito cometido pelo réu tenha acontecido há mais de 4 anos antes de descoberto pelas autoridades. Desse modo, se desde a denúncia até o trânsito em julgado da condenação definitiva do indivíduo houver decorrido o prazo prescricional, acarretar-se-á a extinção da punibilidade do agente.

A corrupção dentro da Administração Pública se desenvolve em um ambiente sem testemunhas, tornando muito difícil o trabalho das autoridades em descobrir a prática de tais delitos, investigá-los, processá-los e julgá-los antes de corrido o prazo prescricional. 
Para evitar que a Operação Lava Jato tenha o mesmo fim da Mãos Limpas, no que diz respeito à impunidade, vem-se agilizando o desenvolvimento das investigações e do próprio processo, considerando - ainda que erroneamente - as delações como verdades absolutas no processo, como se fossem provas propriamente ditas. Tal entendimento é equivocado, vez que a própria Lei n. 12.850/2013 a definiu como mero meio de obtenção de prova, em seu art. $3^{\circ}$, o que, em tese, deveria impedir que o processo girasse em torno delas. E é em relação a essa temática que se desenvolve o elo entre o Caso Tortora e as problemáticas envolvendo o futuro da colaboração premiada no Brasil.

Como visto, a Itália passou por diversas fases no decorrer da Operação Mani Pulite, a começar pelo sentimento de esperança em um país melhor, que rapidamente foi devastado pela frustração dos resultados obtidos. O Brasil vem passando pela mesma situação que a Itália viveu anos atrás, ainda na fase, a priori, ilusória de que efetivas mudanças ocorrerão no cenário político brasileiro. Resta torcer para que o país aprenda com os erros lá cometidos para que o mesmo não venha a acontecer aqui, sem olvidar que atitudes desesperadas para evitar tais fins fracassados podem também prejudicar e arruinar os objetivos de uma operação contra organizações criminosas, como no caso de Enzo Tortora.

\section{O CASO TORTORA}

"Io sono qui, e lo so anche, per parlare per conto di quelli che parlare non possono, e sono molti, e sono troppi; sarò qui, resterò qui, anche per loro", ou seja, "Eu estou aqui, e sei também, para falar por aqueles que falar não podem, e são muitos, e são vários; estarei aqui, permanecerei aqui, também por eles" (MOROSI; RASTELLI, 2018). Foi com essas palavras que Enzo Tortora, famoso apresentador de televisão italiano que sofreu as consequências de delações falsas nos anos 80 , retornou pela primeira vez ao 
seu programa Portobello após a sua absolvição pela justiça.

O Caso Tortora pode até ter ocorrido na Itália há muitos anos, mas as suas consequências permanecem até hoje e podem servir de guia para que o Brasil evite tornar um inocente em bode expiatório em uma tentativa fracassada de conter os sentimentos de impunidade e de descrença nas instituições democráticas que transbordam no país.

O uso equivocado de uma colaboração premiada como prova é perigoso quando as informações prestadas pelo delator são inverídicas ou omitem fatos, distorcendo a realidade do que se investiga. O processo acaba girando em torno da delação e usando como guia algo que não é verdadeiro, o que atrapalha - e muito as investigações e a realização da tão clamada justiça. Nesse ponto, entra o caso de Enzo Tortora, ocorrido na Itália nos anos 80 . Tortora era considerado um dos fundadores da televisão italiana e viu-se privado de sua liberdade e julgado por quase todo um país como mafioso, membro da máfia Nuova Camorra Organizzata, ainda que sem provas robustas de seu suposto crime.

Giovanni Pandico, membro da organização criminosa, viu a oportunidade de redimir sua pena e acusou Tortora. Ele conseguiu transformar um episódio envolvendo centrini di seta (toalhas de crochê) enviados ao estúdio do apresentador por seu colega de cela, Domenico Barbaro, na prisão de Porto Azzurro, na ilha de Elba, para serem leiloadas no seu popular programa Portobello em prova de que Tortora era um traficante de drogas e comunicava-se com os mafiosos por meio de códigos.

Foi encontrada uma agenda na casa de outro mafioso, Giuseppe Puca, com escritos que pareciam ser o nome do apresentador, mas que, mais tarde, foi descoberto que diziam respeito a um depósito de bebidas, Tortona, o que acabou por corroborar a delação. Além disso, outros mafiosos, todos apresentando versões discrepantes entre si, aproveitaram da oportunidade que surgira de obter benefícios processuais sem ter que delatar 
o envolvimento de outrem na organização criminosa.

A ação do pintor Giuseppe Margutti, que relatou às autoridades ter visto Tortora comercializar drogas nos estúdios de

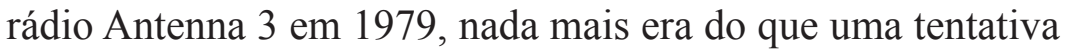
de chamar atenção para si em uma jogada de marketing para vender mais obras. Não obstante à estranheza, as autoridades no decorrer das investigações nunca duvidaram da palavra do pintor, cujo histórico criminal por crimes de fraude e calúnia era extenso. (PETRINI; ROSA; COPETTI NETO, 2015).

Em nenhum momento a veracidade das delações foi questionada, mesmo estando óbvia a existência de um problema, principalmente as discrepâncias nas versões apresentadas pelos mafiosos, incompatíveis não só entre si, como também com a realidade. Gianni Melluso, por exemplo, afirmou em juízo ter entregue pessoalmente um quilo de cocaína a Tortora entre o final do ano de 1975 e o início de 1976, sendo que, posteriormente, foi atestado que, durante o período apontado pelo delator, o mesmo encontrava-se preso em Sciacca, tornando a entrega da substância impossível.

Em posse de tais "provas", as autoridades italianas promoveram a prisão de Tortora em 17 de junho de 1983 no Hotel Plaza di Roma, marcando o início do fim de sua vida. A partir de tal data, uma grande operação contra a máfia Nuova Camorra Organizzata foi deflagrada, tendo o apresentador permanecido preso por sete meses até ter a sua liberdade decretada.

Em 17 de setembro de 1985, Tortora veio a ser condenado em primeiro grau pela prática do delito de associação criminosa de tipo mafioso e por tráfico de drogas, nos termos do artigo 416-bis do Código Penal italiano (PETRINI; ROSA; COPETTI NETO, 2015). Sua pena foi arbitrada em 10 anos de reclusão somados ao pagamento de 50 milhões de liras.

Na sentença condenatória, o juiz Luigi Sansone, Presidente 
do Tribunale di Napoli, foi incisivo sobre a participação de Tortora na máfia Camorra, apontando o caráter desprezível do apresentador, ainda que nenhuma das provas colhidas no processo dessem a entender tal versão. Segundo o magistrado, Tortora não só deixou de comprovar a sua inocência e de trazer uma explicação para toda a conspiração que contra ele se formara, como também "[...] demonstrou ser um indivíduo extremamente perigoso, conseguindo esconder por anos suas atividades sombrias e seu verdadeiro rosto, aquele de um cínico comerciante da morte, ainda mais pernicioso porque coberto por uma máscara de cortesia e savoir fair" (PEZZINI, 2017, tradução nossa). ${ }^{4}$

Foi apenas no ano seguinte que Tortora veio a ser absolvido em sede de apelo pela Corte di Appello di Napoli, absolvição que veio a ser confirmada pela Corte di Cassazione, em 17 de junho de 1987, exatamente quatro anos depois de sua prisão (NAZZI, 2010).

Todavia, mesmo absolvido, Enzo Tortora não foi de nenhuma forma ressarcido pelos abusos e danos sofridos. Nenhum dos envolvidos, como falsos delatores e os magistrados e membros da acusação, foram responsabilizados pelo grosseiro erro judiciário. Em verdade, a partir do fato, os magistrados e procuradores atuantes no caso foram promovidos, vindo a ocupar cargos mais altos no Judiciário do país. O juiz Luigi Sansone, por exemplo, tornou-se Presidente da Sexta Secção Penal da Corte di Cassazione (PETRINI; ROSA; COPETTI NETO, 2015).

Buscando reparação pelos danos sofridos, Tortora ajuizou uma ação contra os juízes que o condenaram, pleiteando uma indenização de 100 milhões de liras, a qual foi arquivada pelo Conselho da Magistratura.

Ainda em 1987, um referendum foi realizado para ques-

4 “[...] ha dimostrato di essere un individuo estremamente pericoloso, riuscendo a nascondere per anni le sue losche attività e il suo vero volto, quello di un cinico mercante di morte, tanto più pernicioso perché coperto da una maschera di cortesia e savoir fair". 
tionar a responsabilidade civil dos magistrados, por meio da retirada dos arts. 55, 56 e 74 do Código de Processo Civil italiano, dispositivos que impediam a responsabilização pessoal de magistrados em caso de erros judiciários. A maioria da população italiana com direito a voto opinou pelo provimento do referendum, mas, antes que pudesse surtir efeitos, entrou em vigor a Legge Vassali, Lei n. 117/1988, que anulou os resultados da pesquisa feita, mantendo a impossibilidade de responsabilização pessoal de magistrados por erros (PETRINI; ROSA; COPETTI NETO, 2015).

Portanto, o que se observou no Caso Tortora foi que, mesmo sofrendo um chocante abuso estatal, que culminou na revolta do país contra a sua pessoa, Enzo Tortora não foi compensado. Aliás, o único resultado de toda a situação que se formara desde 1983 foi o falecimento do apresentador em decorrência de um câncer de pulmão, em 18 de maio de 1988. Entretanto, ainda assim muitas pessoas o consideravam culpado, como um verdadeiro camorrista(NAZZI, 2010).

No Brasil, nota-se essa mesma sensação de revolta e indignação que a população italiana tinha e continua tendo com relação às instituições democráticas de seu país. Por isso, na pressa e ansiedade de resolver o problema da corrupção no país, a delação pode vir a ser utilizada como uma prova propriamente dita e não como um meio de obtenção de prova, que é o que ela legalmente é.

A Lei n. 12.850/2013 é clara nesse sentido. Em seu art. $3^{\circ}$, a normativa expressamente elenca a colaboração premiada em um rol de meios de obtenção de prova, que nada mais são do que

[...] todos aqueles que o juiz, direta ou indiretamente, utiliza para conhecer da verdade dos fatos, estejam eles previstos em Lei ou não. Em outras palavras, é o caminho utilizado pelo magistrado para formar a sua convicção acerca dos fatos ou coisas que as partes alegam. (RANGEL, 2018, p. 481). 
Dessa forma, uma colaboração, em tese, não deve estar desacompanhada no processo de outras provas que a corroborem, tampouco pode ser causa exclusiva para a condenação do agente objeto da delação. Para não haver interpretações diversas, o legislador buscou deixar claro, no $\S 16$ do art. $4^{\circ}$ da Lei n. 12.850/2013 que: "Nenhuma sentença condenatória será proferida com fundamento apenas nas declarações de agente colaborador". (BRASIL, 2013).

A delação no Brasil é muito complicada de ser trabalhada quando usada como base a Lei n. 12.850/2013. São inegáveis os avanços trazidos com a normativa das organizações criminosas, porém há uma lacuna no que diz respeito ao modo como os acordos de colaboração premiada são firmados, cabendo à prática defini-lo, em especial, à Operação Lava Jato. Por isso, não se olvidam as fortes críticas que muitos fazem à delação, apontando-a como um instrumento imoral, que desprestigia princípios fundamentais do direito penal como a presunção da inocência ao trocar a colaboração do réu pela sua renúncia ao direito de contestar sua culpa.

No entanto, o problema não é o instituto em si e sim a falta de regulamentação e a sua própria aplicação prática que é deixada aos casos concretos. Muito embora a justiça negocial não seja um instituto recente na história do ordenamento jurídico brasileiro, foi apenas há poucos anos que passou a chamar a atenção da população e dos juristas em geral.

A qualidade das informações prestadas por um insider (quem tem acesso à informações privilegiadas) é muitas vezes melhor do que a obtida por alguém que precisou juntar os fragmentos indiciários/probatórios, daí por que o valor de um delator não pode ser desprezado pela eventual repugnância diante de sua atitude em trair. A ausência de delatores torna tarefa investigativa complexa, demorada e cara. (ROSA, 2018, p. 15).

O processo penal brasileiro não nasceu para ser negocia- 
do. Desde a entrada em vigor do Código de Processo Penal em 1941, a rigidez e imutabilidade fazem parte do estudo da matéria processual penal no país. A possibilidade de negociar a pena era uma realidade distante até 1995, com a Lei de Juizados Especiais, que trouxe institutos como a transação penal e a suspensão condicional do processo.

Embora não seja uma novidade normativa, a colaboração premiada começou a ter destaque e a chamar a atenção dos juristas apenas com a Operação Lava Jato. Por isso, hoje, muitos juristas ainda se encontram despreparados para lidar com a colaboração premiada ou até mesmo nutridos de má-fé para salvaguardar interesses próprios e alheios, o que acaba por deturpar a letra da lei e burlar o sistema processual penal vigente.

No Brasil, a ausência de regras bem estabelecidas faz com que agentes se lancem a campo desprovidos de protocolos de ação, jogados em sua capacidade intuitiva, com riscos ainda maiores de serem engolfados em práticas ilícitas a que mesmo de boa-fé estão sujeitos. A ambiguidade normativa e mesmo a ausência de regras promove o império do tirocínio investigativo e sedimenta práticas de improviso realizadas em cobertura legal. Afinal de contas a ausência de regras poderia ser argumento retórico de que não se violou a legalidade. (ROSA, 2018, p. 301).

Aqui, mais uma vez, a questão cultural é elemento predominante. No Brasil, a cultura do famoso "jeitinho brasileiro", de se conseguir o que se quer com o menor custo possível e sem seguir as regras da sociedade, é algo que passa para o processo penal, ainda que muitos não admitam. Acaba sendo raro que algum dos envolvidos em acordos de delação tenham a lei em seu melhor interesse.

Resumidamente, o que aconteceu no caso de Enzo Tortora foi isto: membros da máfia Camorra viram a oportunidade de usufruir dos benefícios da delação sem ter que delatar nenhum chefe da máfia de verdade e, consequentemente, sem ter de 
sofrer qualquer represália - a realidade de muitos dos collaboratori di giustizia (como são chamados os delatores na Itália).

Os magistrados e policiais envolvidos no caso, buscando autopromoção em cima da repercussão midiática que se formava ao redor de Tortora, tampouco se atentaram ao ordenamento jurídico italiano, tudo em prol da condenação do apresentador. Tanto é que na data da prisão inicial de Tortora na madrugada de 17 de junho de 1983, os Carabinieri - como são chamados os policiais italianos - aguardaram até meio dia para só então realizarem a transferência do apresentador da delegacia para a prisão de Regina Coeli. Isso tudo para dar tempo para que a notícia da prisão se propagasse, reunindo jornalistas, fotógrafos e curiosos para presenciar a cena de um dos mais carismáticos apresentadores de televisão do país sair da delegacia algemado.

Com isso, um instrumento tão interessante como o direito premial acaba se tornando sinônimo de algo negativo para muitos, não por ser um instituto ruim, mas, sobretudo, em razão do mau uso por parte de juristas e dos próprios delatores que deturpam o instituto para satisfazer seus próprios interesses a todo custo. Ocorreu na Itália e pode acontecer no Brasil também.

\section{CONCLUSÃO}

O ponto a que se deve atentar é o fato de que o Brasil vem imitando a Itália em diversas questões. Isso é incontroverso, ainda que não seja de maneira proposital, já que a raiz dos problemas de ambos os países é cultural no que diz respeito, principalmente, à impunidade de crimes de organizações criminosas contra a Administração Pública. Como afirma Rodrigo Chemim (2017, p. 09), “Ainda que a Itália seja um país europeu, a percepção que os próprios italianos têm é de que ela não segue o mesmo padrão ético de outros países do continente e nesse ponto se aproxima muito mais do Brasil do que de seus vizinhos". 
Basta olhar o modo como os políticos italianos e brasileiros reagem quando envolvidos em escândalos de corrupção, algo que não se vê em outros países, em que os investigados preferem deixar o cargo, mesmo que se digam inocentes, para não prejudicar o interesse público.

Se, na Itália, uma delação falsa em meio à angústia de combater a corrupção e a máfia teve os efeitos desastrosos vistos no caso de Enzo Tortora, e o Brasil se inspira tanto naquele país, isso é sinal de que devemos nos atentar para que o mesmo não venha a acontecer aqui.

O instituto da colaboração premiada não só deve ser mantido, como também aprimorado, utilizando-se como base a história de outro ordenamento jurídico semelhante. É uma realidade que não se pode negar. Vários países, como Itália e Estados Unidos, fazem uso de mecanismos de negociação no processo penal há muito tempo, cada qual da sua forma, então não será o Brasil o único a trilhar por caminho diverso, ignorando as tendências mundiais, como bem disse Alexandre Morais da Rosa (2018, p. 198).

A delação é um importante instrumento de combate à corrupção, principalmente em razão do fato de este tipo de criminalidade se desenvolver entre quatro paredes, sendo muito difícil para que as autoridades tomem conhecimento da sua prática e consigam buscar soluções antes de decorrido o prazo prescricional. Afinal, é por meio das informações prestadas por ex-membros de organizações criminosas que a estrutura e funcionamento destas tornam-se conhecidas publicamente.

A delação é um instituto que, por muitos, pode ser visto como um mal necessário, mas que, em verdade, não passa de um bem, que busca otimizar o processo penal, mas que acaba deturpado por juristas que usam de um instrumento processual para lucrar sobre uma situação, até mesmo como meio de vingança entre membros de uma organização criminosa. 
Não há como controlar os motivos que levam alguém a delatar. Muito se fala em colaboração nos dias de hoje, tratando-a como se fosse a solução para os problemas do Brasil. No entanto, pouco se fala dos perigos que a circundam quando deixada a sua regulamentação a ser ditada pelos casos concretos e a sua aplicação prática nas mãos desesperadas das autoridades quem correm contra o tempo para evitar que seu esforço seja frustrado pela prescrição. Entender o que aconteceu na Itália, principalmente estando visível que esse país vem sendo usado como fonte de inspiração no Brasil, em especial, na Operação Lava Jato, é essencial para entender e tentar prever possíveis erros e corrigi-los aqui antes que seja tarde demais, como acabou sendo para Enzo Tortora.

\section{REFERÊNCIAS}

BIONDANI, Paolo. 25 anni di Mani pulite, i 10 verbali che hanno cambiato l'Italia: da Mario Chiesa alla maxi tangente Enimont. Dalle mazzette rosse a Berlusconi. Tangentopoli e la fine della Prima Repubblica. Le confessioni che hanno rivelato i segreti del potere in versione integrale. 2017. Disponível em: http://espresso.repubblica. it/attualita/2017/02/15/news/mani-pulite-i-10-verbali-che-hanno-cambiato-l-italia-leconfessioni-nelle-carte-originali-1.295481. Acesso em: 02 out. 2018.

BITENCOURT, Cezar Roberto. Código penal comentado. 9. ed. São Paulo: Saraiva, 2015.

BRASIL. Lei $\mathbf{n}^{\mathbf{0}} \mathbf{1 2 . 8 5 0}$, de 02 de agosto de 2013. Define organização criminosa e dispõe sobre a investigação criminal, os meios de obtenção da prova, infrações penais correlatas e o procedimento criminal; altera o Decreto-Lei no 2.848, de 7 de dezembro de 1940 (Código Penal); revoga a Lei no 9.034, de 3 de maio de 1995; e dá outras providências. Lei n. 12.850, de 2 de Agosto de 2013. Brasília, DF, 05 ago. 2013. Disponível em: http://www.planalto.gov.br/ccivil_03/_ato2011-2014/2013/lei/112850.htm. Acesso em: 02 out. 2018.

BRASIL. Ministério Público Federal. A lava jato em números no Paraná. 2018a. Disponível em: http://www.mpf.mp.br/para-o-cidadao/caso-lava-jato/atuacao-na-1ainstancia/parana/resultado. Acesso em: 02 out. 2018.

BRASIL. Ministério Público Federal. A lava jato em números no Rio de Janeiro. 2018b. Disponível em: http://www.mpf.mp.br/para-o-cidadao/caso-lava-jato/atuacaona-1a-instancia/rio-de-janeiro/resultados. Acesso em: 02 out. 2018.

BRASIL. Ministério Público Federal. Termo de acordo de colaboração premiada de Paulo Roberto Costa. Curitiba, 2014. Disponível em: https:/www.conjur.com.br/dl/ acordo-delacao-premiada-paulo-roberto.pdf. Acesso em: 02 out. 2018.

CHEMIM, Rodrigo. Mãos limpas e lava jato: a corrupção se olha no espelho. Porto 
Alegre: Citadel, 2017.

DALLAGNOL, Deltan. As luzes da delação premiada: a colaboração do delator oferece ao investigador a oportunidade de iluminar o labirinto da corrupção e descobrir os melhores caminhos para desvendá-lo. 2015a. Disponível em: https://epoca.globo.com/ tempo/noticia/2015/07/luzes-da-delacao-premiada.html. Acesso em: 02 out. 2018.

DALLAGNOL, Deltan. Brasil é o paraíso da impunidade para réus do colarinho branco. 2015b. Disponível em: https://noticias.uol.com.br/opiniao/coluna/2015/10/01/brasil-eo-paraiso-da-impunidade-para-reus-do-colarinho-branco.htm. Acesso em: 02 out. 2018.

MORO, Sergio Fernando. Considerações sobre a operação mani pulite. Revista Cej, Brasília, v. 8, n. 26, p. 56-62, jul./set. 2004. Disponível em: https://bdjur.stj.jus.br/jspui/ handle/2011/114782. Acesso em: 04 out. 2018.

MOROSI, Silvia; RASTELLI, Paolo. Enzo Tortora, 30 anni dalla morte di un uomo innocente. 2018. Disponível em: http://pochestorie.corriere.it/2018/05/18/enzo-tortora-30-anni-dalla-morte-di-un-uomo-innocente/. Acesso em: 03 out. 2018.

NAVARRIA, Giovanni. Looking back at 1992: Italy's horrible year. 2016. Disponível em: https://theconversation.com/looking-back-at-1992-italys-horrible-year-66739. Acesso em: 02 out. 2018.

NAZZI, Stefano. Il giorno in cui arrestarono Enzo Tortora. 2010. Disponível em: https://www.ilpost.it/stefanonazzi/2010/09/17/il-giorno-in-cui-condannarono-enzo-tortora/. Acesso em: 03 out. 2018.

PETRINI, Michela; ROSA, Alexandre Morais da; COPETTI NETO, Alfredo. Delações falsas e o que nos pode ensinar o caso Tortora da Itália: $O$ perigoso jogo dos "colaboratori di giustizia". 2015. Disponível em: http://emporiododireito.com.br/ leitura/delacoes-falsas-e-o-que-nos-pode-ensinar-o-caso-tortora-da-italia-o-perigosojogo-dos. Acesso em: 03 out. 2018.

PEZZINI, Alberto. Di errore giudiziario si può morire: dedicato agli innocenti condannati e agli avvocati che resistono. 2017. Disponível em: https://www.avvocatirandogurrieri.it/leggi-e-diritto/di-errore-giudiziario-si-puo-morire-dedicato-agli-innocenti-condannati-e-agli-avvocati-che-resistono. Acesso em: 02 out. 2018.

RANGEL, Paulo. Direito processual penal. 26. ed. São Paulo: Atlas, 2018.

ROSA, Alexandre Morais da. Guia compacto do processo penal conforme a teoria dos jogos. 3. ed. Florianópolis: Empório do Direito, 2016.

ROSA, Alexandre Morais da. Para entender a delação premiada pela teoria dos jogos: táticas e estratégias do negócio jurídico. Florianópolis: EModara, 2018.

SANTE, Kirios di. Cosa fu la tangente enimont: L'interpretazione dei fatti relativi alla madre delle tangenti appare univoca: l'ennesima ipostatizzazione della corruzione primorepubblicana. Ma il significato economico della vicenda potrebbe dirci dell'altro. 2015. Disponível em: https://www.lintellettualedissidente.it/economia/cosa-fu-la-tangente-enimont/ . Acesso em: 03 out. 2018.

Recebido em: 17/02/2019

Aprovado em: 25/06/2019 